\title{
Calcined and natural frustules filled epoxy matrices: The effect of volume fraction on the tensile and compression behavior
}

\author{
E.A. Gültürk, M. Güden, A. Taşdemirci* \\ Dynamic Testing and Modeling Laboratory and Department of Mechanical Engineering, Izmir Institute of Technology, Gulbahçe, Urla, Izmir, Turkey
}

\section{A R T I C L E I N F O}

\section{Article history:}

Received 28 November 2011

Received in revised form 3 January 2012

Accepted 29 March 2012

Available online 5 April 2012

\section{Keywords:}

A. Polymer-matrix composites (PMCs)

B. Mechanical properties

B. Impact behavior

D. Mechanical testing

\begin{abstract}
A B S T R A C T
The effects of calcined diatom (CD) and natural diatom (ND) frustules filling (0-12 vol.\%) on the quasistatic tensile and quasi-static and high strain rate compression behavior of an epoxy matrix were investigated experimentally. The high strain rate testing of frustules-filled and neat epoxy samples was performed in a compression Split Hopkinson Pressure Bar set-up. The frustules filling increased the stress values at a constant strain and decreased the tensile failure strains of the epoxy matrix. Compression tests results showed that frustules filling of epoxy increased both elastic modulus and yield strength values at quasi-static and high strain rates. While, a higher strengthening effect and strain rate sensitivity were found with ND frustules filling. Microscopic observations revealed two main compression deformation modes at quasi-static strain rates: the debonding of the frustules from the epoxy and/or crushing of the frustules. However, the failure of the filled composites at high strain rates was dominated by the fracture of epoxy matrix.
\end{abstract}

(c) 2012 Elsevier Ltd. All rights reserved.

\section{Introduction}

Diatoms are single-celled algae of the class Bacilariophyceae of the phylum Baciloriophyta [1]. These unicellular microscopic plants inhabit aquatic and moist environments and are responsible for the world primary food production. The skeleton of the diatoms, known as frustules or siliceous shell, is made of nano-size silica with a three-dimensional intricate framework [2-5]. Each diatom frustules has species specific regularly arrayed features; pores, ridges and protuberance. The size of frustules ranges between 1 and $500 \mu \mathrm{m}$, while the characteristic dimensions of features between 10 and $200 \mathrm{~nm}$ [6,7]. When diatom cells die, the silica shells deposit on the ocean floor and form diatomaceous earth (DE) or diatomite. Diatomaceous earth is an abundant, inexpensive material and extensively used in sound and heat insulation, abrasives, filters, absorbents and explosives [8]. One potential engineering application is the templates or scaffolds for the processing of three-dimensional complex micro-scale polymeric, metallic and ceramic structures [7,9-11]. The other potential applications include gas-selective metal film membranes, pin-point drug delivery (magnetized frustules) and processing nano-powder silica (high-energy ball milling, ultrasonic waves and electrical and thermal shock) [12].

The mechanical properties of individual diatom frustules were previously investigated and shown to vary with the location of

\footnotetext{
* Corresponding author. Address: Izmir Institute of Technology, Gulbahçe Koyu, Urla, Izmir 35430, Turkey. Tel.: +90 232 7506780; fax: +90 2327506701.

E-mail address: alpertasdemirci@iyte.edu.tr (A. Taşdemirci).
}

the measurements taken, which was attributed to the different stages of the bio-mineralization process [2]. The elastic moduli of the diatom frustule of Thalassiosira Punctigera and Naviculapelliclosa were reported 22.4 GPa [13] and 7-100 GPa [2], respectively. The energy needed to break the frustules and the area of the fracture were further shown to be relatively high as the cracks travelled around $\sim 40 \mathrm{~nm}$ silica particles of the diatom frustules [14]. In addition, the frustules have relatively high surface area, measured as high as $11.777 \mathrm{~m}^{2} \mathrm{~g}^{-1}$ [15] and $22 \mathrm{~m}^{2} \mathrm{~g}^{-1}$ [13] and regularly arrayed pores, permitting the penetration of thermoset resins through nano and micro-pores [7]. This makes diatom frustules to be potentially used as reinforcing phase and/or filler in polymeric matrices. In a previous study, a centric type diatom filling of an epoxy resin with a $15 \mathrm{wt} . \%$ addition was shown to increase both compression modulus and yield strength at quasi-static and high strain rates [16]. The present report is an extension of the previous study and focuses on the effects of diatom frustule volume percentages on the compression and tensile mechanical properties of an epoxy matrix at quasi-static and high strain rates. The filling was performed using two different additions; calcined diatom (CD) and natural diatom (ND) frustules.

\section{Materials and experiments}

\subsection{Frustules characterization and treatment}

Calcined diatom frustules, obtained as diatomaceous earth filter material from a domestic vendor (Celatoms FW-60 grade from EaglePicher Filtration \& Mineral, Inc., USA), were mostly cylindrical 
in shape and appeared as short tubes with diameters of 8-15 $\mu \mathrm{m}$ and lengths of $3-20 \mu \mathrm{m}$ (Fig. 1a). These frustules contained rows of fine pores, $300-500 \mathrm{~nm}$ in diameter, aligned parallel to the tube-axis. Natural diatom frustules (Johnson Matthey Co., England) were composed of various types of frustules species, including pennate and centric types as shown in Fig. 1b. The particle size distribution of frustules was determined in water with and without ultra-sonication using a Mastersizer Particle Size Analyzer. The compositions of the frustules were determined using an X-ray Florescence spectrometer (XRF) (Spectra IQ II). The phases of the frustules were determined using a Philips X'PertPro X-ray Diffraction with a $\mathrm{Cu} \mathrm{K \alpha}$ radiation $\left(\lambda=1.54 \mathrm{~A}^{\circ}, 40 \mathrm{kV}\right)$.

Before filling, ND frustules were heat-treated at $600{ }^{\circ} \mathrm{C}$ for $2 \mathrm{~h}$ in order to remove the residual organic matter from the surface of the frustules. Both frustules were washed with ethanol and then with deionized water several times in order to dissolve and remove large pieces of salts. The powders were then wet-sieved below 325 meshes to eliminate the insoluble relatively large particles. The small, broken frustules pieces were removed partly by sedimentation in deionized water. A suspension of the frustules was prepared and allowed to settle out for $1 \mathrm{~h}$ and then the decantate containing small or broken frustules pieces was poured out. This procedure was repeated three times and the remnant was dried at $120^{\circ} \mathrm{C}$ for $2 \mathrm{~h}$ in an oven before mixing with epoxy resin to prepare the filled epoxy matrices.

\subsection{Composite test specimen preparation}

A commercial epoxy resin Grandmer ${ }^{\circledR} \mathrm{VN}-111$ with a hardener was used as the matrix. The epoxy resin was mixed with diatom frustules using an Ultra-Turrax Homogenizator at 20,000 rpm. After degassing under vacuum, the hardener was added and the

(a)

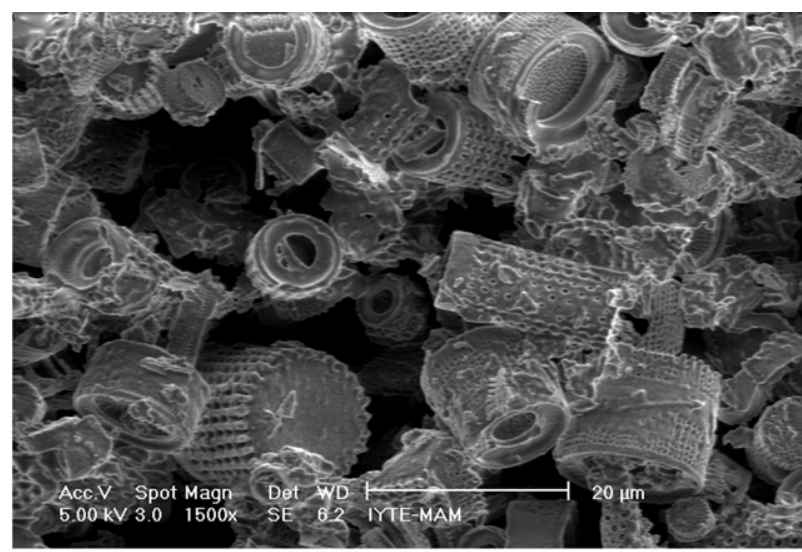

(b)

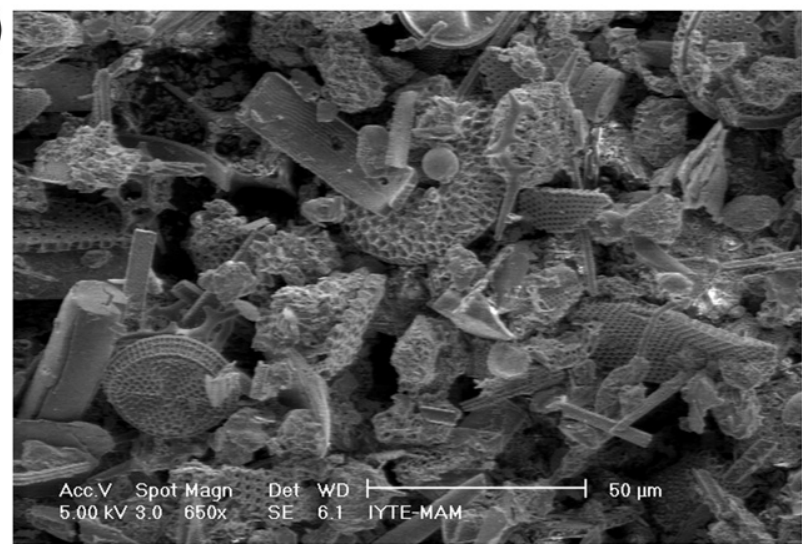

Fig. 1. SEM micrographs showing (a) CD frustules and (b) ND frustules. solution was gently mixed in order to avoid gas bubble formation. The polymer/frustules mixture was then cast into to the Teflon molds in the form of the tension test coupons (Fig. 2a) in accord with ASTM D638M-91a standard (Fig. 2b). The thickness of test specimens was reduced to $4.0 \pm 0.1 \mathrm{~mm}$ by grinding the surfaces of the specimens in a milling machine. In another route of experiments, neat resin and frustules-filled epoxy plates, $8.0 \times$ $8.0 \times 1.5 \mathrm{~cm}$ in size, were cast into a Teflon mold separately. Cylindrical compression test specimens, $9.7 \mathrm{~mm}$ in diameter and $14.0 \mathrm{~mm}$ in length, were then core-drilled from these cast epoxy plates. Neat epoxy and filled test specimens were cured at room temperature for $24 \mathrm{~h}$ followed by a post curing process at $110^{\circ} \mathrm{C}$ for $5 \mathrm{~h}$. The thermal gravimetric analyses of the neat epoxy and frustules-filled composites were performed using a Shimadzu Thermal Gravimetric Analyzer (TGA) in a dry nitrogen atmosphere $\left(40 \mathrm{ml} \mathrm{min}^{-1}\right)$ from room temperature up to $500{ }^{\circ} \mathrm{C}$ with a heating rate of $10^{\circ} \mathrm{C} \mathrm{min}^{-1}$. The volume fraction of frustules in filled epoxy samples $\left(V_{f}\right)$ was determined from weight losses of TGA analysis using the following equation:

$$
V_{f}=\frac{W_{f}}{W_{f}+\left(1-W_{f}\right) \frac{\rho_{f}}{\rho_{m}}}
$$

where $W_{f}$ is the filler weight fraction and $\rho_{f}$ and $\rho_{m}$ are the densities of filler $\left(2.33 \mathrm{~g} \mathrm{~cm}^{-3}\right)$ and matrix $\left(1.135 \mathrm{~g} \mathrm{~cm}^{-3}\right)$, respectively.

\subsection{Mechanical testing}

Quasi-static tension tests were performed at a strain rate of $1 \times 10^{-3} \mathrm{~s}^{-1}$ and quasi-static compression tests were performed at the strain rates of $1 \times 10^{-3}$ and $1 \times 10^{-1} \mathrm{~s}^{-1}$, using a Shimadzu AG-I test machine. The displacements of the tested specimens

(a)

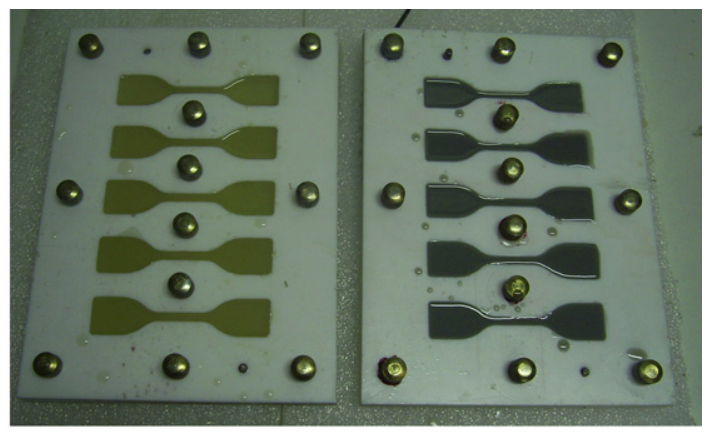

(b)

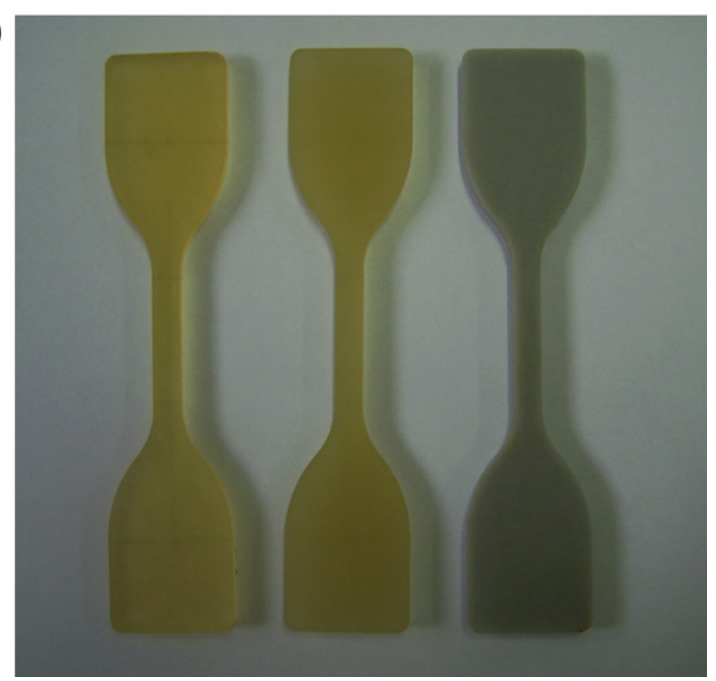

Fig. 2. Tension test (a) sample coupons molding and (b) samples. 
were recorded using a video extensometer directly connected to the testing machine. High strain rate compression tests were performed in a compression type Split Hopkinson Pressure Bar (SHPB) set-up at the strain rates between 300 and $600 \mathrm{~s}^{-1}$. The schematic of the SHPB apparatus used in the tests is shown in Fig. 3 and consists of a $19.05 \mathrm{~mm}$ diameter Inconel $718 \mathrm{bar} ; 3450 \mathrm{~mm}$ long incident bar, $1850 \mathrm{~mm}$ long transmitter bar and $71 \mathrm{~mm}$ long striker bar. The strain rate $(\dot{\varepsilon})$, strain $(\varepsilon)$ and stress $(\sigma)$ in the specimen in SHPB testing are calculated using the following equations based on one-dimensional wave propagation in long bars:

$\dot{\varepsilon}(t)=\frac{-2 C_{b}}{L_{s}} \varepsilon_{r}(t)$

$\varepsilon(t)=\frac{-2 C_{b}}{L_{s}} \int_{0}^{t} \varepsilon_{r}(t) d t$

$\sigma(t)=\frac{E_{b} A_{b}}{A_{s}} \varepsilon_{t}(t)$

where $C_{b}$ is the elastic wave velocity of the bar, $L_{s}$ is the sample length, $t$ is the time and $A_{s}$ and $A_{b}$ are the sample and bar cross-sectional area, respectively. $\varepsilon_{r}$ and $\varepsilon_{t}$ are the reflected and transmitted strains measured from strain gages on the bar, respectively. Typical SHPB incident and transmitted wave records as function of time is shown in Fig. 4a. The corresponding stress-strain and strain ratestrain graphs are further shown in Fig. 4b. As noted in the same figure, the strain rate varies during a test; therefore, an average strain rate is calculated between the strain corresponding to the maximum strain rate and the final attained strain in Fig. 4b. The compressive strength is taken as the maximum stress in the stress-strain curve and the compression elastic modulus $(E)$ is measured from the slope of the stress-strain curve in the elastic region as shown in Fig. 4b. At least three tension and compression tests were performed at quasi-static and high strain rates for each group of material.

\section{Results}

\subsection{Diatom frustules}

Fig. 5 shows the particle size distribution of the frustules with and without ultrasonic dispersion. The mean particle size of $C D$ frustules is $42.60 \mu \mathrm{m}$ and the applied ultrasonic treatment for 2 min reduces the mean particle size to $36.82 \mu \mathrm{m}$. Ninety percent of $\mathrm{CD}$ frustules are smaller than $113.72 \mu \mathrm{m}$ and $10 \%$ less than $12.35 \mu \mathrm{m}$. Ninety percent of ND frustules are smaller than $54.37 \mu \mathrm{m}$ and $10 \%$ less than $3.964 \mu \mathrm{m}$. The ultrasonic dispersion reduces the mean particle size from $16.79 \mu \mathrm{m}$ to $15.09 \mu \mathrm{m}$. CD and ND frustules are mainly consisted of silica mineral (88-90\%) and varying concentrations of other oxide elements as tabulated in Table 1. XRD spectra of the as-received CD frustules in Fig. 6 show crystalline cristobalite silica (tetragonal form of silica) peaks, which is in accord with the supplier's specification of the crystalline silica ranging between 40 and $70 \mathrm{wt}$.\%. This is known as the Opal C structure, a well-ordered form of the silicate [17]. While,
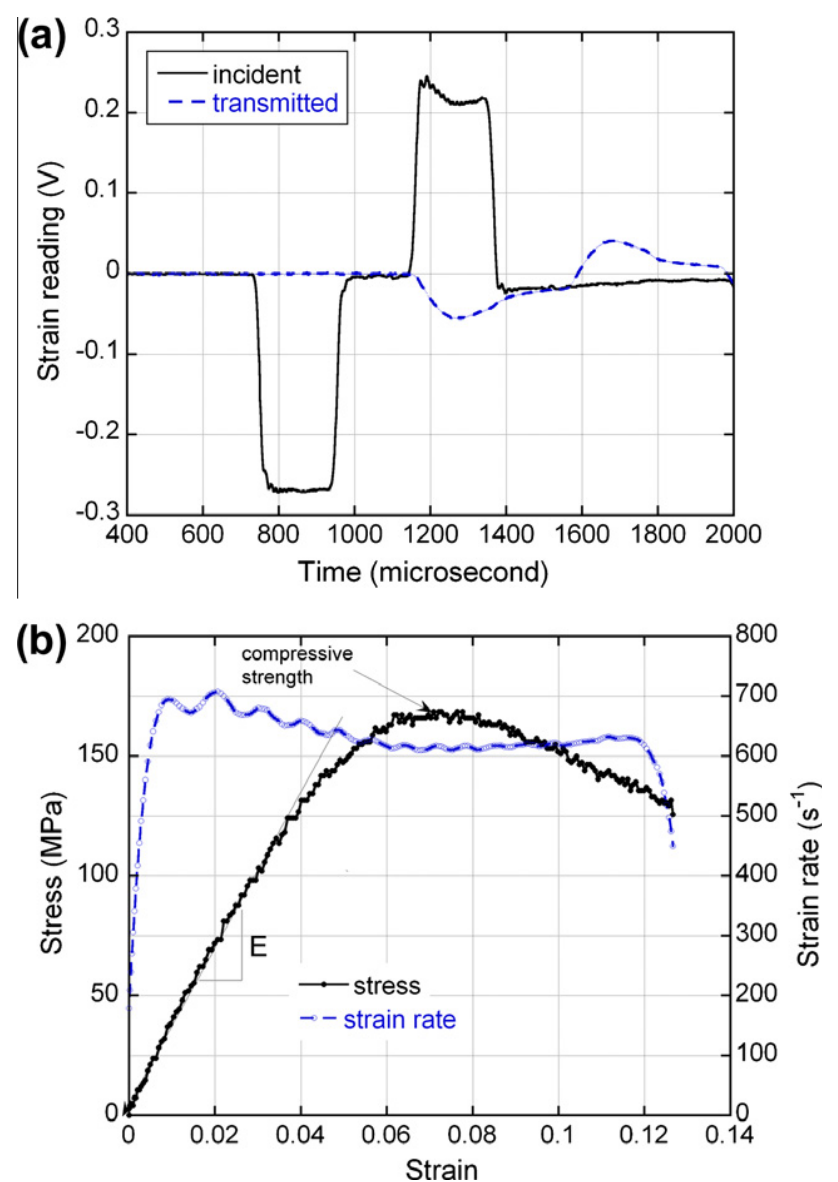

Fig. 4. Typical (a) incident and transmitted wave-time and (b) stress-strain ratestrain curves of neat epoxy.

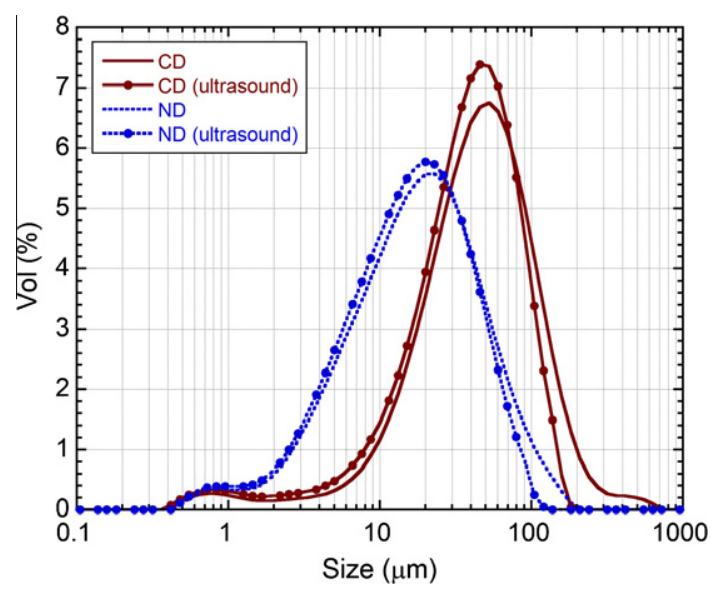

Fig. 5. The particle size distribution of $\mathrm{CD}$ and ND frustules.

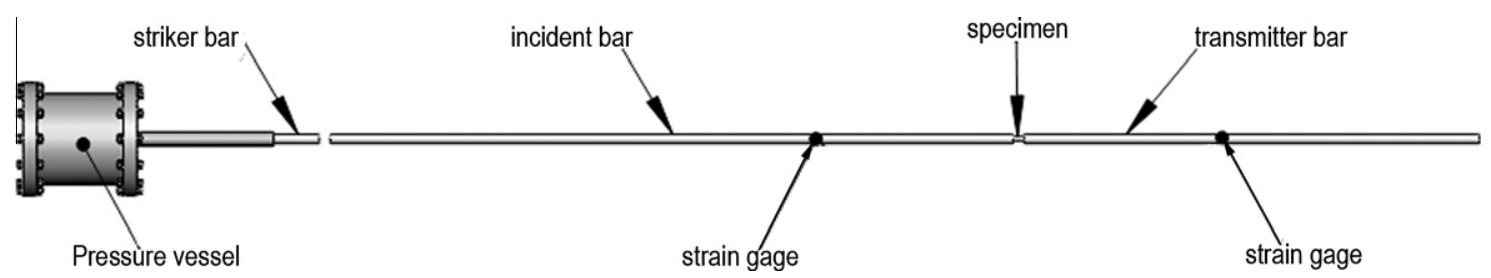

Fig. 3. Schematic of compression SHPB set-up. 
Table 1

The composition of flux-calcined (CD) and natural diatomite (ND) frustules.

\begin{tabular}{|c|c|c|c|c|c|c|c|c|c|c|c|}
\hline Elements & $\mathrm{SiO}_{2}$ & $\mathrm{Al}_{2} \mathrm{O}_{3}$ & $\mathrm{Fe}_{2} \mathrm{O}_{3}$ & $\mathrm{CaO}$ & $\mathrm{MgO}$ & $\mathrm{TiO}_{2}$ & $\mathrm{Na}_{2} \mathrm{O}$ & $\mathrm{P}_{2} \mathrm{O}_{5}$ & $\mathrm{MnO}$ & $\mathrm{K}_{2} \mathrm{O}$ & $\mathrm{Cr}_{2} \mathrm{O}_{3}$ \\
\hline CD (\%) & 88.16 & 5.02 & 1.83 & 0.6 & 0.41 & 0.19 & 2.78 & 0.02 & $<0.002$ & 0.031 & 0.084 \\
\hline ND (\%) & 90.08 & 5.53 & 0.52 & 0.51 & 1.03 & 0.21 & $<0.02$ & 0.23 & $<0.002$ & 0.48 & 0.089 \\
\hline
\end{tabular}

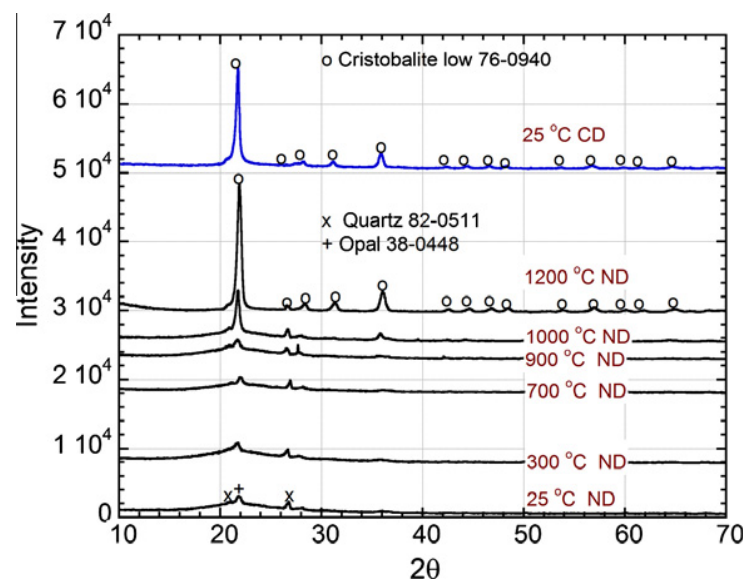

Fig. 6. XRD spectra of $C D$ and heat-treated ND frustules.
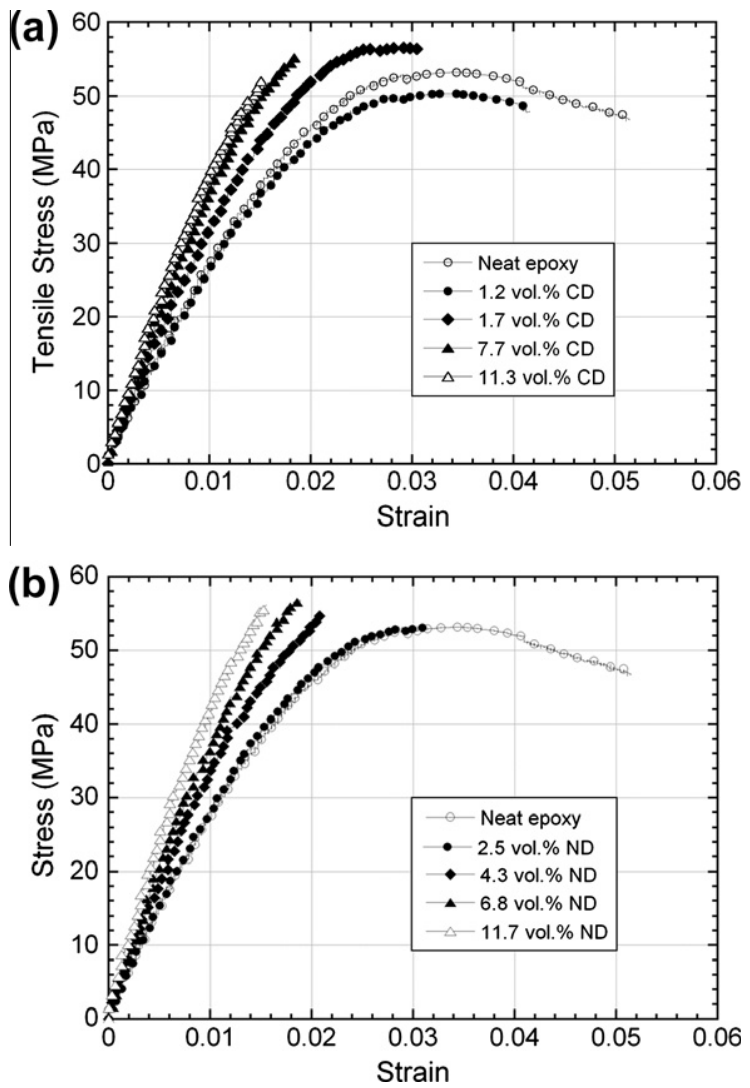

Fig. 7. Tensile stress-strain curves of (a) CD and (b) ND filled epoxy.

ND frustules are in Opal-A structure (Fig. 6), amorphous opal structure with quartz minerals [17]. One hour heat-treatment applied to ND frustules gradually transforms amorphous structure into crystalline cristobalite silica above $900{ }^{\circ} \mathrm{C}$ as shown in Fig. 6 .
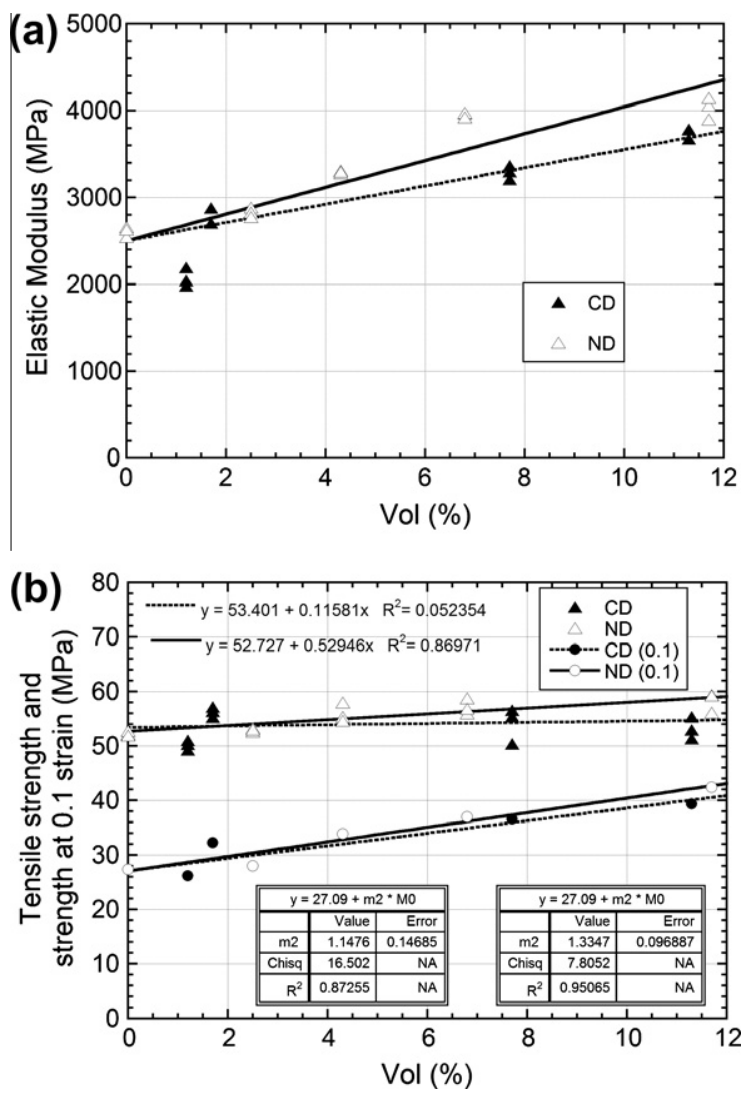

Fig. 8. Variation of (a) elastic moduli and (b) tensile strength and strength at 0.1 strain at varying vol.\% of frustules.

\subsection{Tensile properties}

Quasi-static $\left(1 \times 10^{-3} \mathrm{~s}^{-1)}\right.$ tensile stress-strain graphs of $\mathrm{CD}$ and ND filled epoxies at different frustule volume percentages are shown sequentially in Fig. $7 \mathrm{a}$ and $\mathrm{b}$. The tensile elastic modulus of the neat and filled epoxy is determined by linear fitting of the initial portion of the tensile stress-strain curves. The elastic modulus of filled epoxy increases with increasing vol.\% of frustules addition, except 1.2 vol.\% CD frustules addition (Fig. 7a). The tensile strength (maximum stress) slightly increases with increasing frustules addition as seen in Fig. 7b, while the failure strain decreases with increasing frustules addition. The variations of tensile elastic modulus and tensile strength with vol.\% of frustules addition are further shown in Fig. 8a and b, respectively. It is noted in Fig. 8a that the increase of elastic modulus with increasing frustules vol.\% is more pronounced in ND frustules addition. The elastic modulus increases from $2500 \mathrm{MPa}$ to $4000 \mathrm{MPa}$ at about 12 vol.\%ND frustule addition. The tensile strength increases from $\sim 52 \mathrm{MPa}$ to $\sim 58 \mathrm{MPa}$ on the average at about 12 vol.\% ND frustules addition, while $\mathrm{CD}$ frustule addition has almost no effect on the tensile strength. In Fig. 8b, the average stress corresponding to 0.1 strain is drawn as function vol.\% of frustules addition in order to assess the strengthening effect of frustules addition at a constant 
(a)

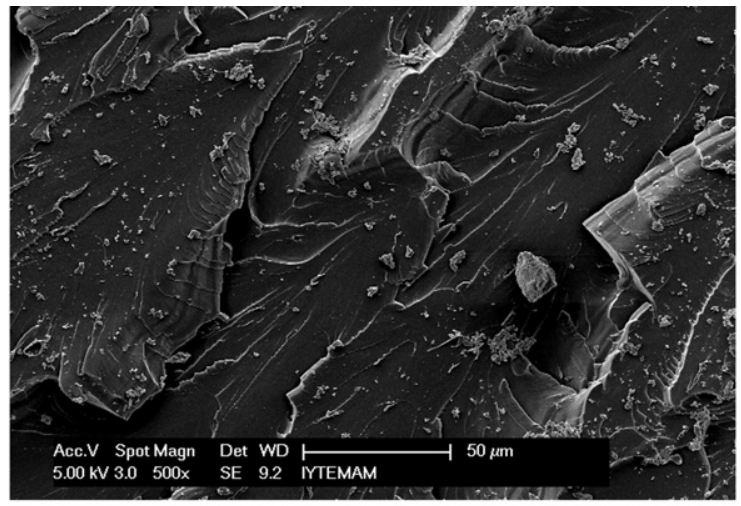

(c)

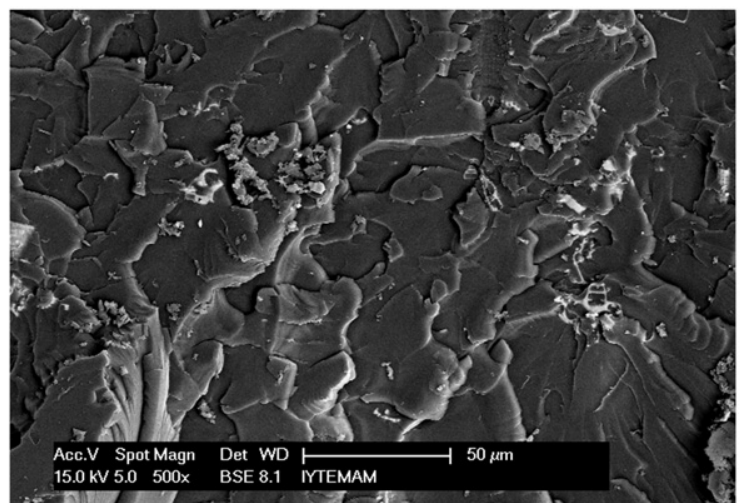

(b)

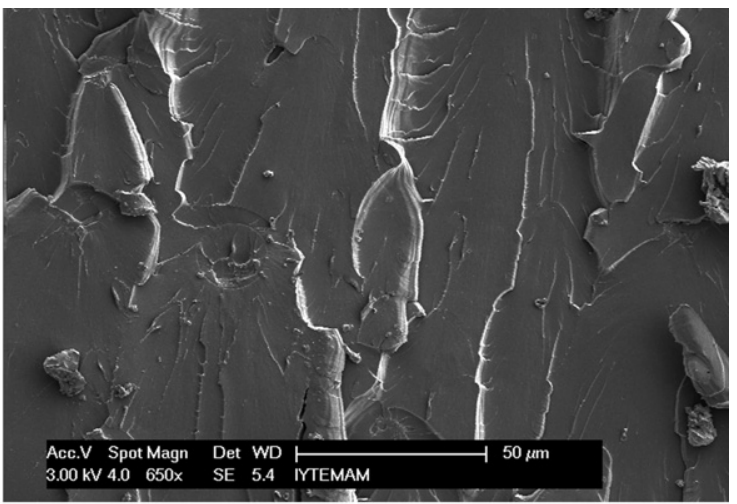

(d)

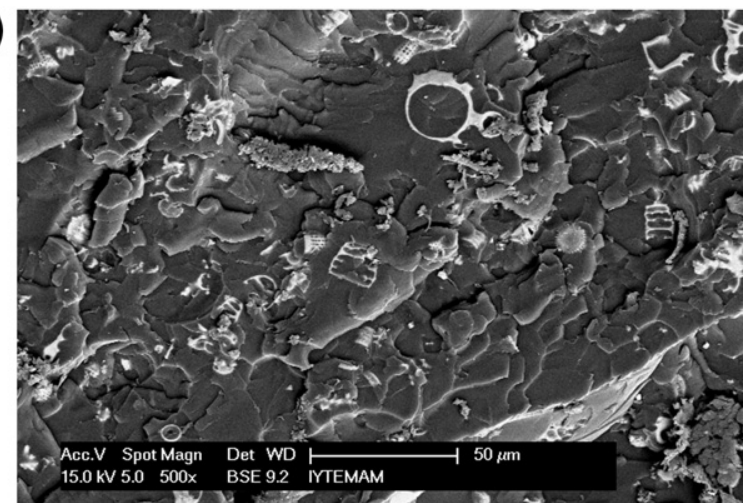

Fig. 9. The SEM micrographs of fracture surfaces of (a) neat epoxy and (b) 1.2 vol.\% (c) 7.7 vol.\% (d) 11.3 vol.\% CD frustules filled epoxy.

strain. As seen in Fig. 8b, both ND and CD frustules additions increase the strength of neat epoxy from $27 \mathrm{MPa}$ to $\sim 40 \mathrm{MPa}$ at 0.1 strain, while the strengthening effect of ND frustule addition seen in the same graph is slightly higher than that of CD frustule addition. These confirmed the strengthening effect of the frustules addition in epoxy matrix. (a)

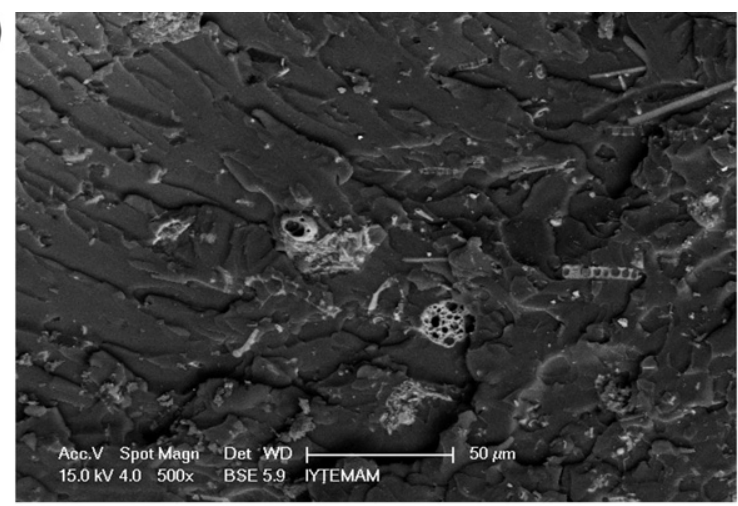

(c)

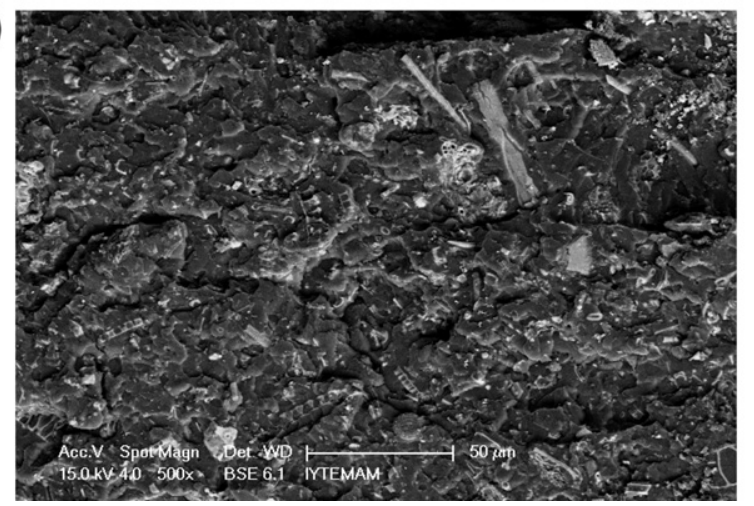

(b)

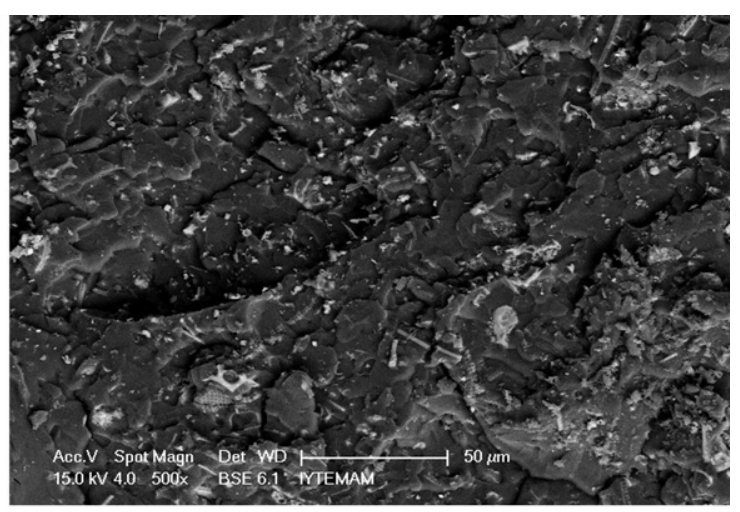

(d)

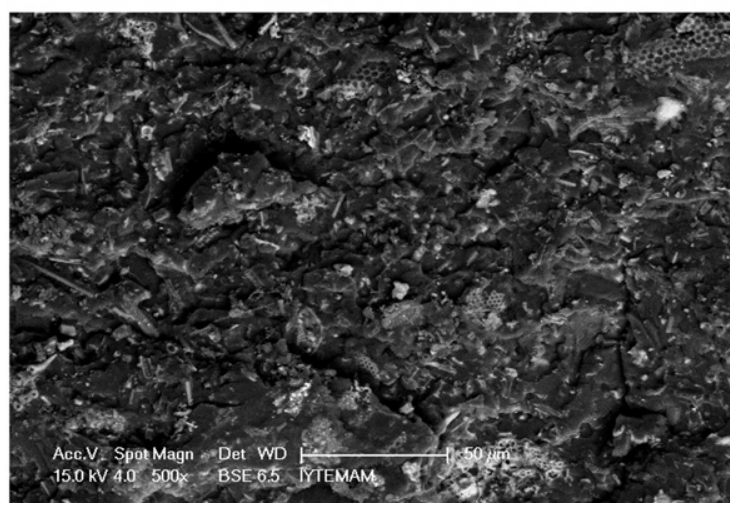

Fig. 10. The SEM micrographs of fracture surfaces of (a) 2.5 vol.\% and (b) 4.3 vol.\% (c) 6.8 vol.\% (d) 11.7 vol.\% ND frustules filled epoxy. 
(a)

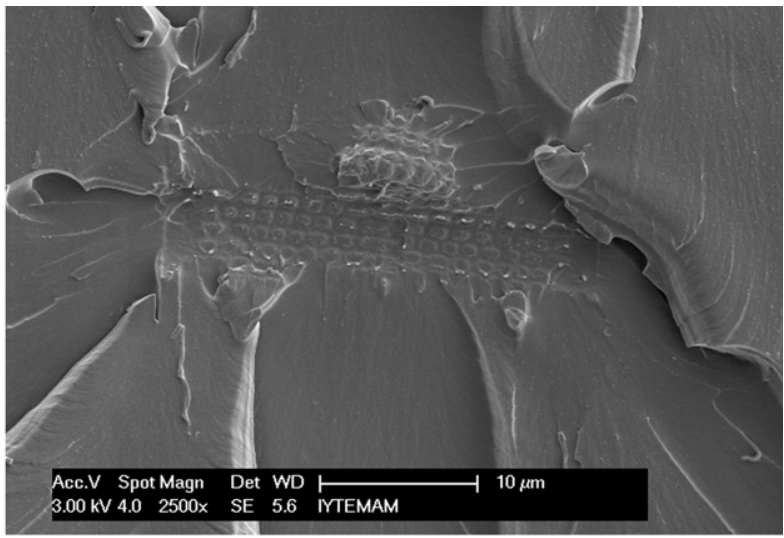

(b)

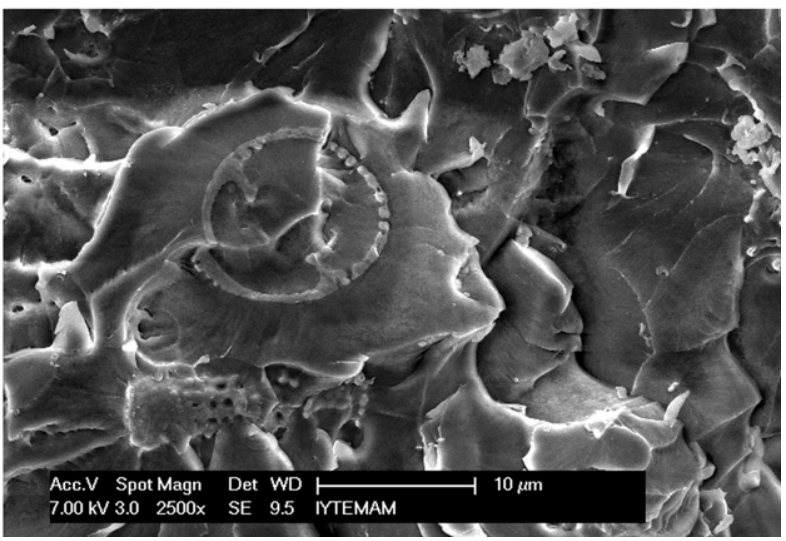

Fig. 11. SEM micrographs of the fracture surfaces of the CD frustules filled epoxy: (a) frustule debonding and (b) frustule fracture and partial pull-out.

The tensile fracture surface of neat epoxy and 1.2, 7.7 and 11.3 vol.\% of CD frustules-filled epoxy specimens are sequentially shown in Fig. 9a-d. The fracture surfaces of neat epoxy resemble the typical fracture surface expected from the brittle thermoset matrices. As the frustule content increases, the fracture surface appearance transforms from wavy form in neat epoxy to ribbed (jagged) form in filled epoxy. For comparison, the tensile fracture surfaces of 2.5, 4.36 .8 and 11.7 vol.\% of ND frustules filled epoxy specimens are shown in Fig. 10a-d, respectively. At the same volume fraction addition, ND frustule filled epoxy samples seem to contain higher number of diatom frustules due to smaller particles size. Therefore, a higher number of frustules are seen on the fracture surfaces of ND frustule filled epoxies (Fig. 10a-d). In connection with this, the jagged surface features are smaller and narrower in ND frustule filled epoxy samples than those in CD frustule filled epoxy samples. Two main tensile failure mechanisms are detected in $C D$ frustule filled epoxy samples: frustules debonding (Fig. 11a) and frustules fracture/crushing followed by partial pull-out (Fig. 11b). In general, debonding is observed in the frustules whose long axis aligned normal to the loading direction as seen in Fig. 11a and fracture is observed in the frustules whose long axis aligned parallel to the loading direction (Fig. 11b). The fracture of individual frustules is attributed to relatively strong frustules adhesion to the epoxy matrix as well as extensive mechanical interlocking. The interlocking is partly due to the epoxy infiltration into the pores on the frustules. This has also been proved with the micrographs of the fracture surfaces of the failed samples. The ligaments of epoxy in the debonded frustules' pores are clearly seen in Fig. 11a. Although, similar failure mechanisms are observed in ND frustules-filled epoxy, as the frustules shape and size are heterogeneous, the identification of the frustules (a)

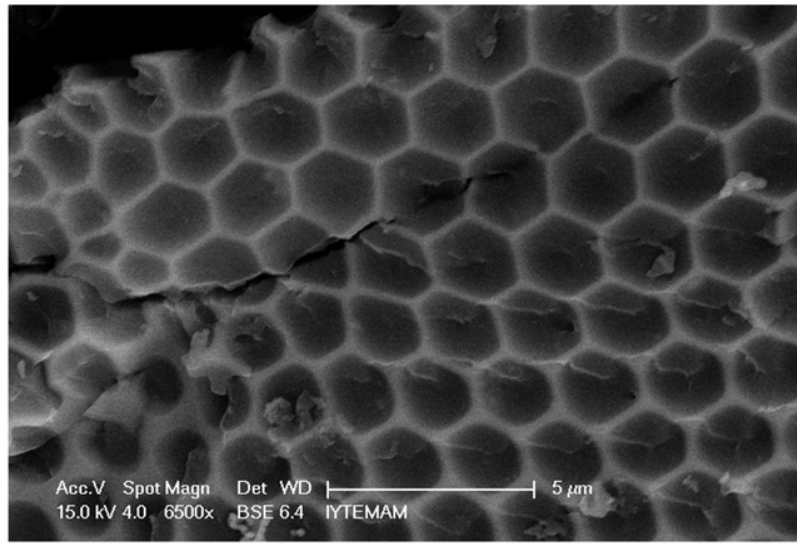

(b)

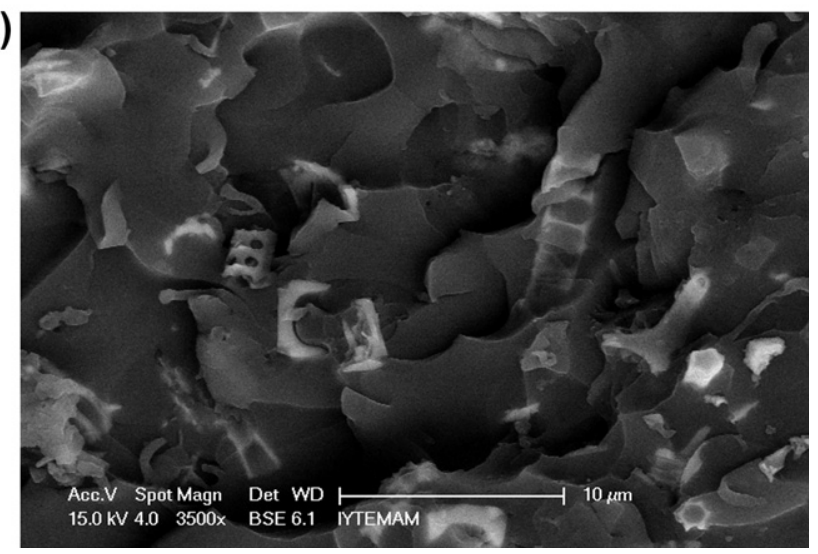

Fig. 12. SEM micrographs of the fracture surfaces of the ND frustules filled epoxy: (a) crack propagation and (b) frustule fracture.

alignment to the loading axis is rather difficult. In Fig. 12a, a hexagonal shaped frustule on the fracture surface of ND frustule filled epoxy is seen. A relatively long crack seen in this figure proceeds through epoxy matrix and is deflected by the frustule wall fracture and frustule debonding. In Fig. 12b, the fractured ND frustules are clearly seen on the fracture surface of a ND filled epoxy sample.

\subsection{Compression properties}

The effect of strain rate on the compression stress-strain curves of CD and ND frustules filled epoxy matrices is seen in Fig. 13a and b, respectively. Increasing strain rate increases the stress values and significantly decreases the compression failure strains of both neat and filled epoxy matrices as shown in Fig. 13a and b. A higher strengthening of ND frustules filled epoxy matrix with increasing strain rate is also noted in Fig. 13a and b. Fig. 14a and b show the variation of the compressive strength values (the initial maximum stress) of CD and ND frustules filled epoxy matrices with the strain rate, respectively. The compressive strength values $\left(\sigma_{c}\right)$ in these figures are fitted with the following relation,

$\sigma_{c}=\sigma_{o}+K \ln \left(\frac{\dot{\varepsilon}}{\dot{\varepsilon}_{o}}\right)$

where $\sigma_{o}$ is the strength at a reference strain rate, $K$ is the strain rate sensitivity parameter and $\dot{\varepsilon}_{o}$ is the reference strain rate. The strain rate sensitivity parameter of the neat epoxy is determined to be $\sim 8$. The strain rate sensitivity parameter increases to 8.75 in 10.8 vol.\% CD frustules filled epoxy and 10.2 in 10.8 vol.\% ND frustules filled epoxy. This further confirms a higher strain rate sensitivity of ND filled epoxy matrices. Fig. 15a and b show the variation of the elastic modulus of $\mathrm{CD}$ and ND frustules filled epoxy matrices 

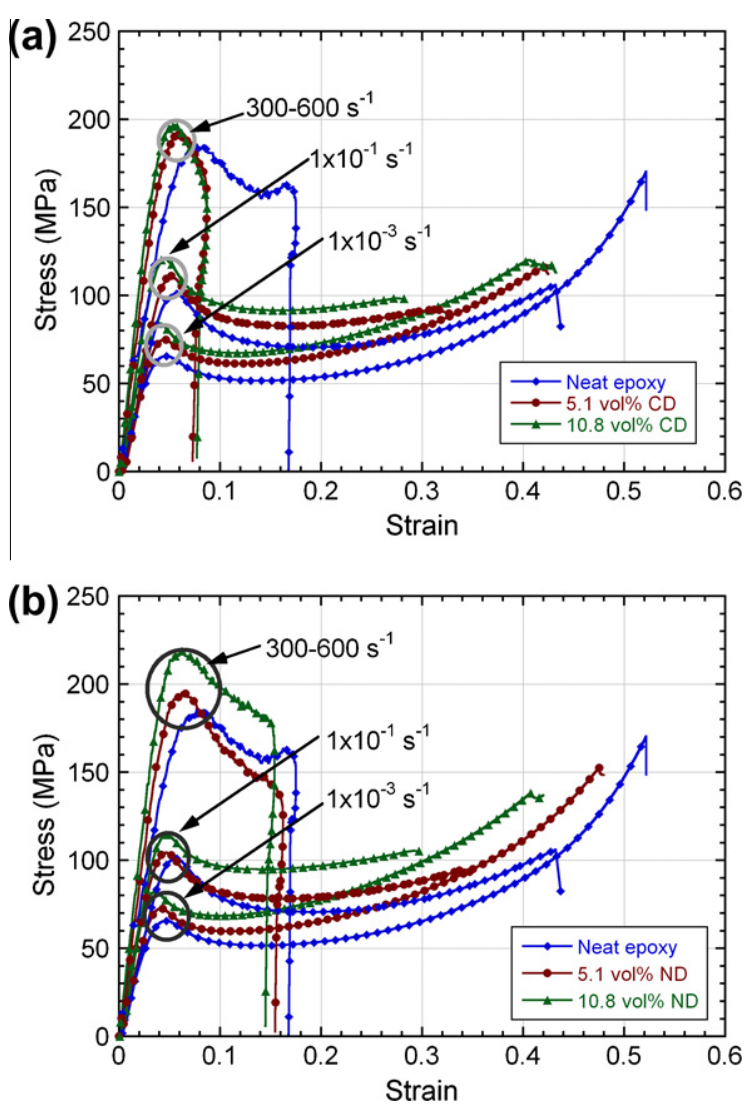

Fig. 13. Compression stress strain curves of (a) CD and (b) ND frustules filled epoxy.

(compression) with the strain rate, respectively. The modulus values are also fitted with Eq. (5). Again an increased strain rate sensitivity parameter is found in filled epoxy matrices. The strain rate sensitivity parameter of elastic modulus for neat epoxy is 96 , while the strain rate parameter increases to about 131 and 141 in 10.8 vol.\% CD and ND filled epoxy matrices, respectively.

The fracture of the neat and filled epoxy matrices tested at quasi-static strain rates is observed to occur through two shear bands progressing $\sim 45^{\circ}$ to the loading axis as shown by the arrows in Fig. 16a. On the other hand, the failure of neat epoxy proceeds with the fracture of a single shear band ( $\sim 45^{\circ}$ to the loading axis) at high strain rate testing in SHPB (Fig. 16b). The filled epoxy matrices of high frustules additions tend to fail through axial splitting in high strain rate tests as shown in Fig. 16b. Microscopic analysis of the fracture surfaces of the samples compression tested at quasi-static strain rates also reveals the debonded and crushed frustules (Fig. 17a). While, the fracture surface of the frustules-filled epoxy matrices tested at high strain rates is seen relatively flat with few or no crushed frustules pieces (Fig. 17b).

\section{Discussion}

Relatively strong frustules adhesion to the epoxy matrix as well as extensive mechanical interlocking is seen on the fracture surfaces of the filled epoxy matrices. The interlocking is due to the epoxy infiltration into the pores of frustules as seen in Figs. 11 and 12. The ligaments of epoxy in the debonded frustules pores seen in Fig. 11a further confirm an efficient epoxy filtration through the pores. In order to identify the deformation/failure mechanism of the filled epoxy, quasi-statically compression tested filled epoxy samples until about failure strain were further cut longitudinally in the mid-section and metallographically prepared for
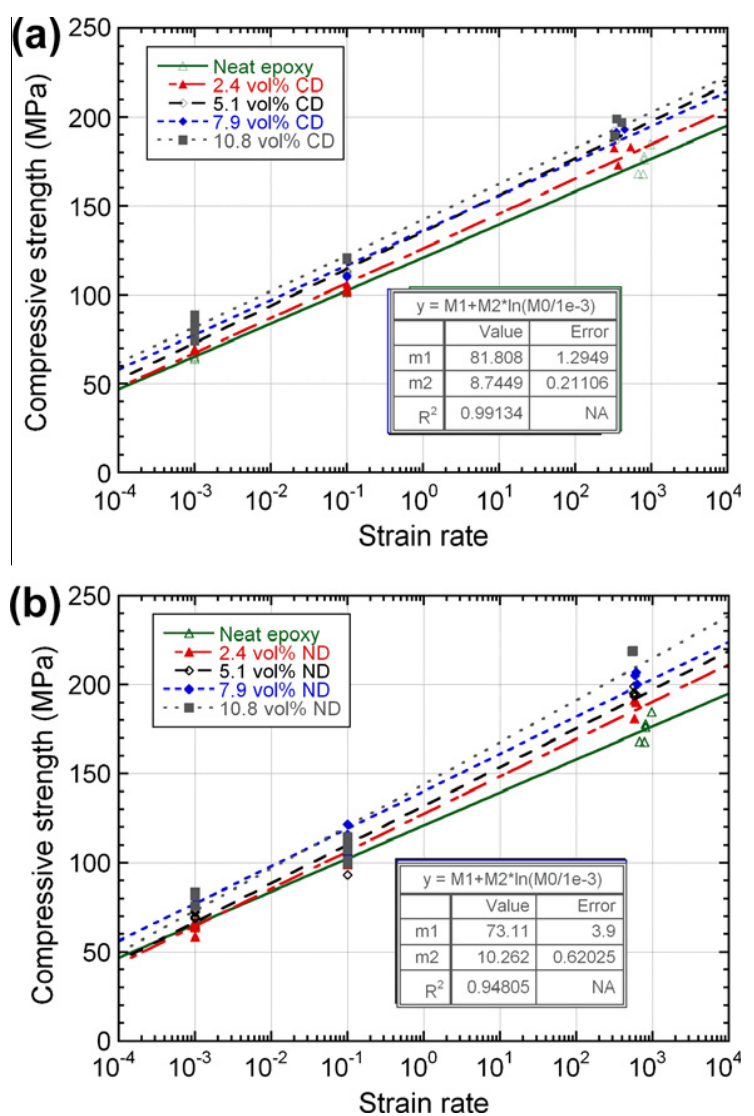

Fig. 14. The variation of the compressive strength values with the strain rate for (a) CD and (b) ND frustules filled epoxy matrices.

the microscopic observations. High strain rate tested axially split filled epoxy samples were also cut and polished for the microscopic observations. Fig. 18a shows an SEM picture of a crack proceeding in a quasi-statically tested ND frustule filled epoxy sample. The crack deflection through the frustules is clearly seen in this figure. At a distance away from the crack site, debonded and fractured frustules are also seen (Fig. 18b). The cracks are further noted to initiate at the debonded/fractured frustules as shown in Fig. 18c. The deformation is tended to be not localized in quasi-statically tested samples. Fig. 19a shows an SEM picture of a high strain rate tested ND filled epoxy sample near the fracture site. No debonding of the frustules is noted to occur near and away from the fracture site (Fig. 19b). The crack seems to proceed in the epoxy matrix and the frustules partially pull-out the epoxy matrix on the fracture site (Fig. 19c). This shows that the failure of the filled epoxy at high strain rates proceeds with the fracture of epoxy matrix, while at quasi-static strain rates failure is dominated by the debonding and crushing of the frustules. In addition, the similar failure strains of ND frustule filled and neat epoxy samples at high strain rates tend to conclude that the failure is matrix dominated.

Several geometrical and material parameters are known to affect the strength and modulus of particulate/short fiber reinforced composites including reinforcement aspect ratio and reinforcement surface area. The aspect ratios of the investigated $C D$ and ND frustules were microscopically determined from SEM pictures (at least 200 frustules lengths and average diameters were measured). The average aspect ratios of ND and CD frustules were found sequentially 4.5 and 2.5 . The determined higher aspect ratio of ND frustules is expected to lead to increased strengthening in ND frustules filled epoxy as compared with CD frustules filled epoxy. The increased surface area may also lead to a higher 

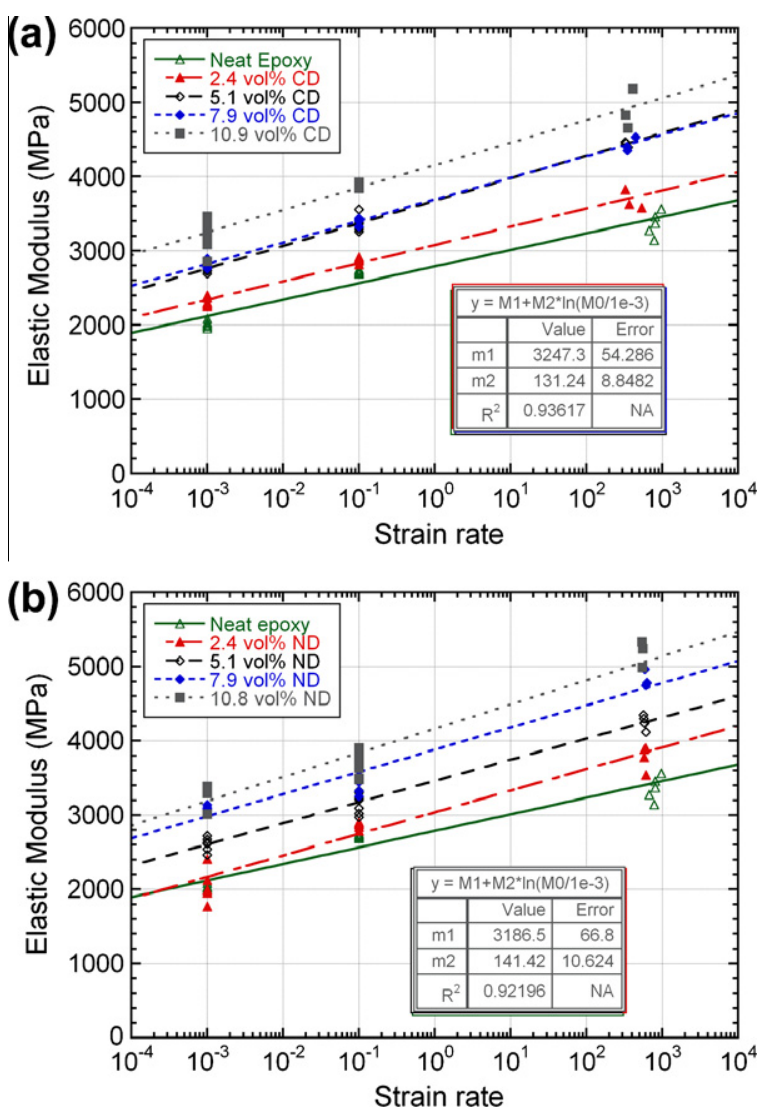

Fig. 15. The variation of the Elastic Modulus values with the strain rate for (a) CD and (b) ND frustules filled epoxy matrices.

mechanical interlocking/gripping between frustule and epoxy hence increased load transfer from matrix to frustules. The mechanical interlocking between frustule and matrix may also be operative in the nanometer-scale, an effect similar to that in non-uniform carbon nano-tube reinforced polymers [18]. This may result in extra energy being expended to deform the matrix. (a)

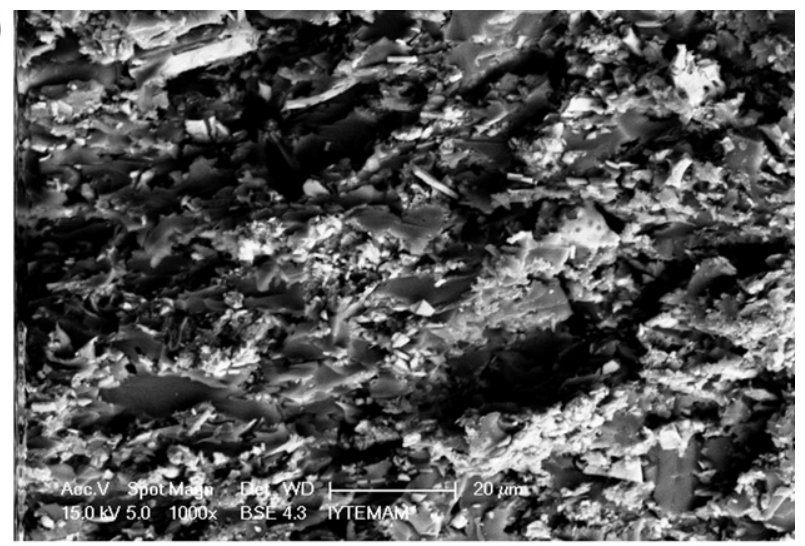

(b)

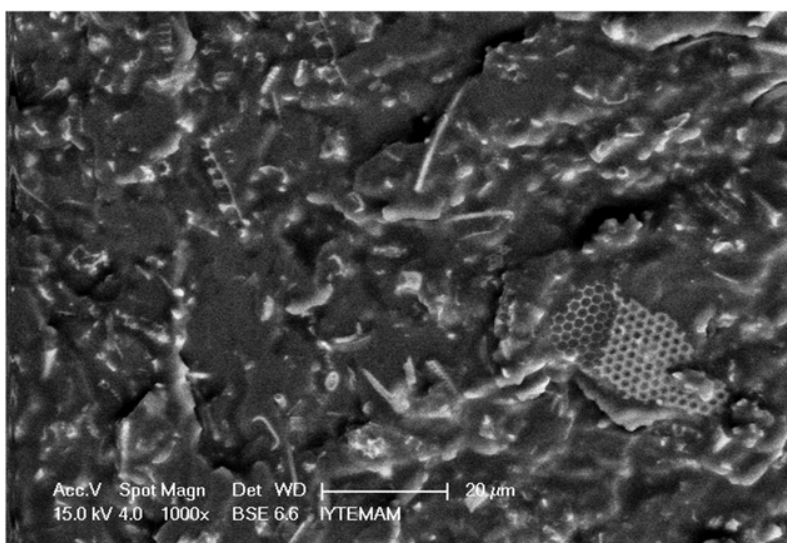

Fig. 17. Microscopic analysis of the fracture surfaces of 10.8 vol.\% ND filled samples compression tested at quasi-static strain rate.

It was previously shown that the applied heat treatment process decreased surface area of frustules [13]. One way of increasing surface area of frustules is to apply acid etching. The surface area of diatomaceous earth, $3.81 \pm 0.01 \mathrm{~m}^{2} \mathrm{~g}^{-1}$, was previously reported to increase $10 \mathrm{~m}^{2} \mathrm{~g}^{-1}$ with acid etching [19]. The effect of acid etching of the frustules on the mechanical behavior filled epoxy matrix will be investigated in future.

(a)

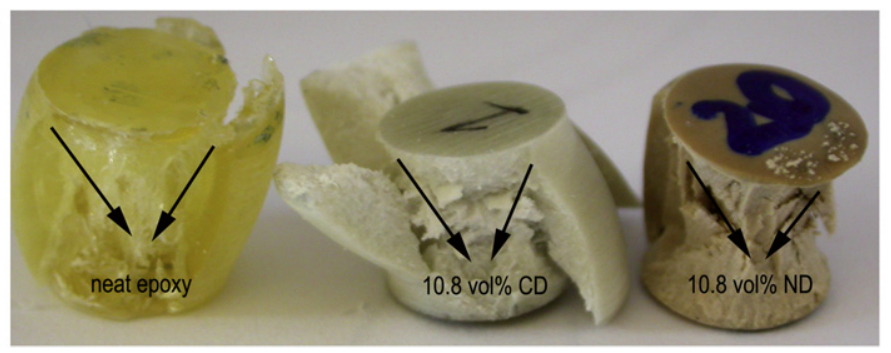

(b)

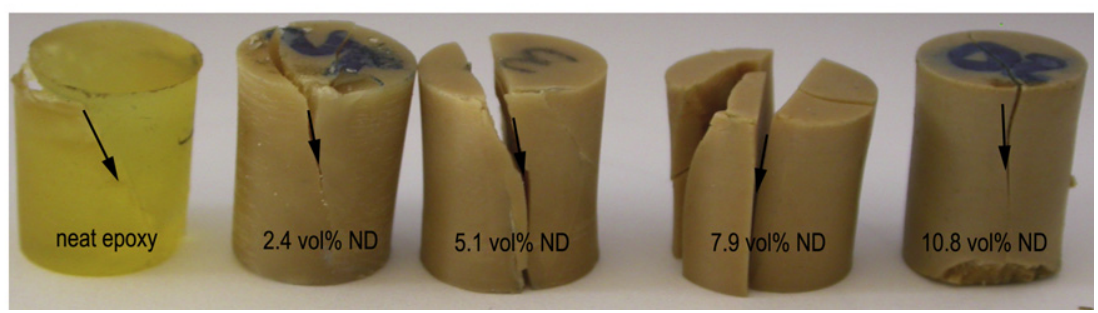

Fig. 16. The pictures of failed compression test samples (a) $1 \times 10^{-3} \mathrm{~s}^{-1}$ and (b) SHPB high strain rate. 
(a)

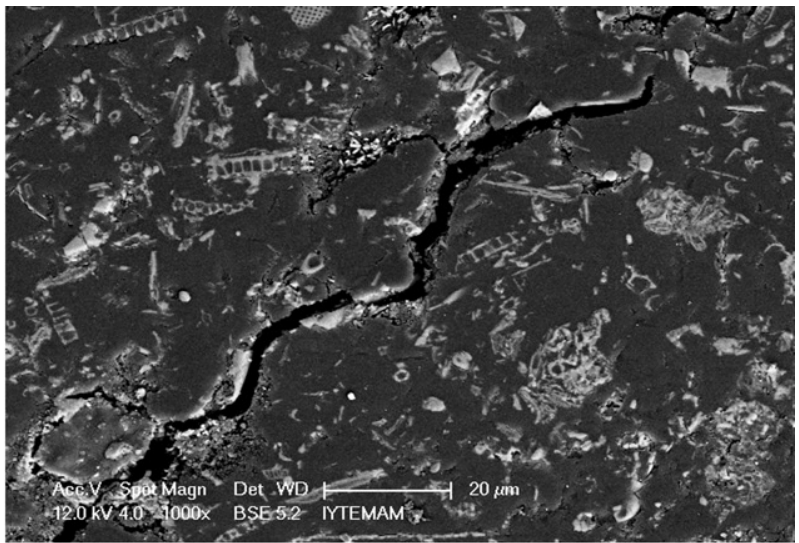

(b)

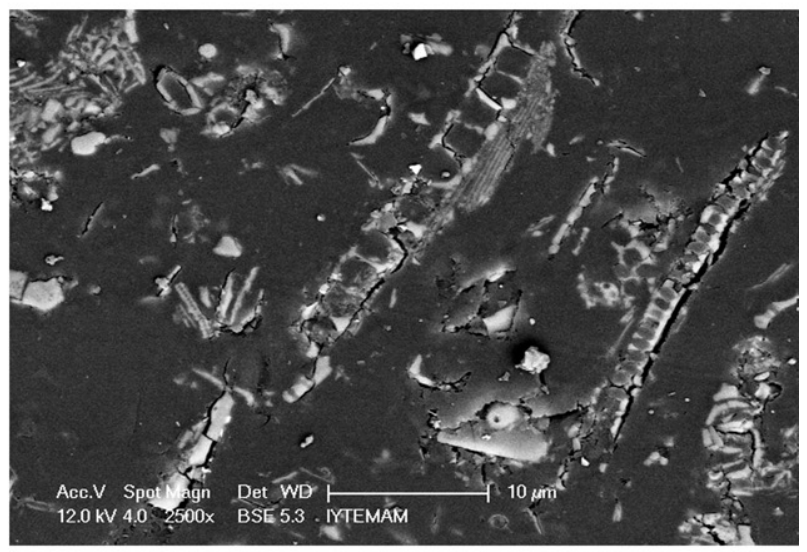

(c)

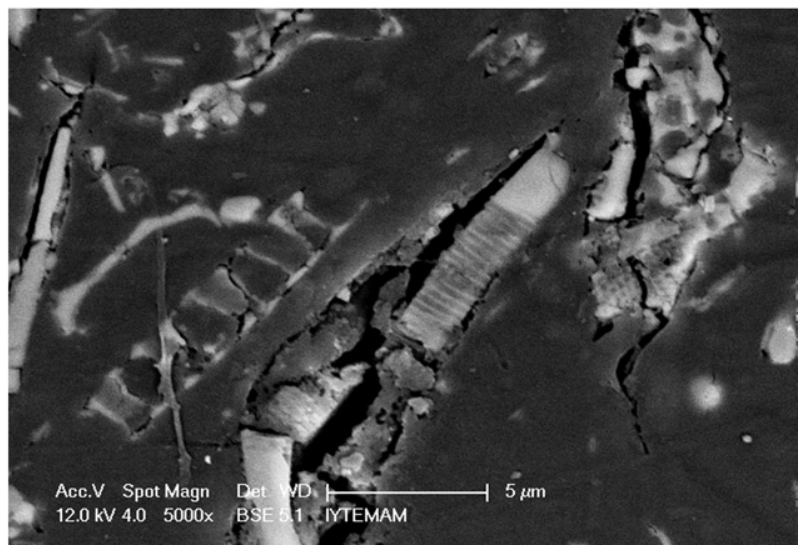

Fig. 18. SEM micrographs of polished cross-section of 10.8 vol.\% ND filled epoxy samples tested at $1 \times 10^{-1} \mathrm{~s}^{-1}$.

\section{Conclusions}

Quasi-static tensile and quasi-static and high strain rate compression behavior of diatom frustules-filled epoxy matrices were investigated experimentally and microscopically. For comparison, the tensile and compression behavior of the neat epoxy were also determined. The frustules filling increased stress values at a constant strain and decreased tensile failure strains of the epoxy matrix. Compression test results have shown that diatom frustules filling increased both modulus and yield strength of the epoxy matrix at quasi-static and high strain rates. Furthermore, ND frustules filled epoxy samples showed higher strain rate sensitivities than CD filled epoxy samples. Microscopic observations revealed two main deformation modes: the debonding of the frustules from the epoxy and crushing/fracture of the frustules at quasi-static (a)

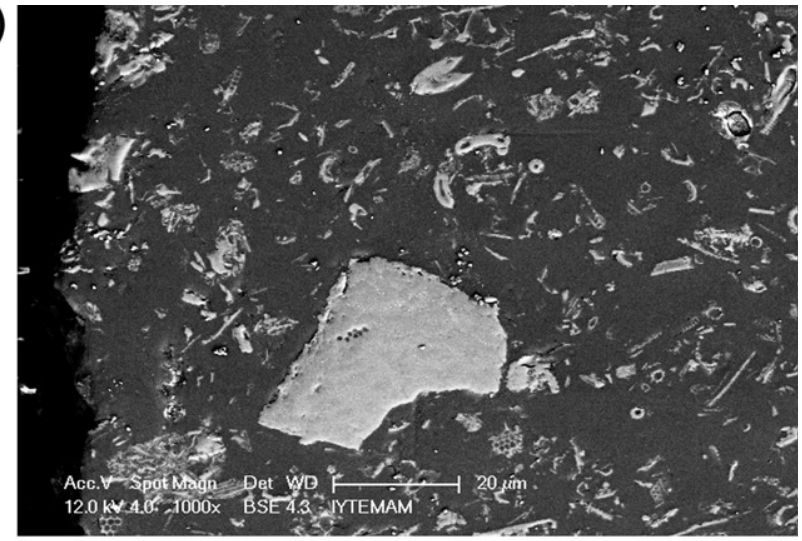

(b)

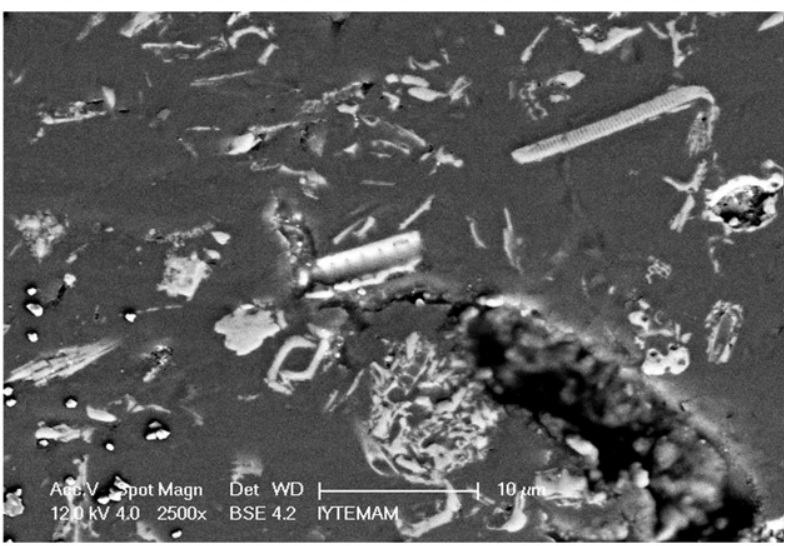

(c)

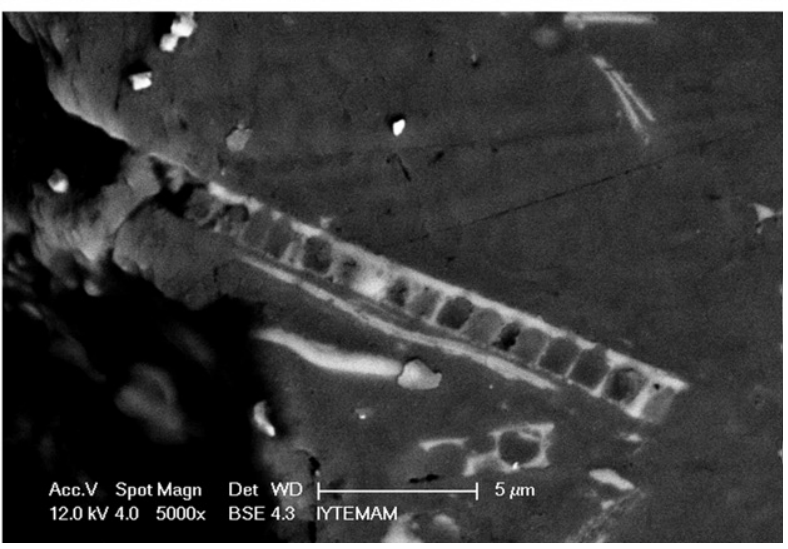

Fig. 19. SEM micrographs of polished cross-section of 10.8 vol.\% ND filled epoxy samples tested at high strain rates.

strain rates, while the failure of the filled composite at high strain rate was dominated by the fracture of the matrices.

\section{References}

[1] Vrieling EG, Beelen TPM, van Santen RA, Gieskes WWC. Diatom silicon biomineralization as an inspirational source of new approaches to silica production. J Biotechnol 1999;70(1-3):39-51.

[2] Almqvist N, Delamo Y, Smith BL, Thomson NH, Bartholdson A, Lal R, et al. Micromechanical and structural properties of a pennate diatom investigated by atomic force microscopy. J Microsc-Oxford 2001;202:518-32.

[3] Anderson MW, Holmes SM, Hanif N, Cundy CS. Hierarchical pore structures through diatom zeolitization. Angew Chem-Int Edit 2000;39(15):2707-10.

[4] Bradbury J. Nature's nanotechnologists: unveiling the secrets of diatoms. PLoS Biol 2004;2(10):306-47.

[5] Cai X, Zhu GS, Zhang WW, Zhao HY, Wang C, Qiu SL, et al. Diatom-templated synthesis of ordered meso/macroporous hierarchical materials. Eur J Inorg Chem 2006;18:3641-5

[6] Fuhrmann T, Landwehr S, El Rharbi-Kucki M, Sumper M. Diatoms as living photonic crystals. Appl Phys B-Lasers Optics 2004;78(3-4):257-60. 
[7] Gaddis CS, Sandhage KH. Freestanding microscale 3D polymeric structures with biologically-derived shapes and nanoscale features. J Mater Res 2004;19(9):2541-5.

[8] Werner D. The biology of diatoms. Berkeley: University of California Press; 1977.

[9] Zhao JP, Gaddis CS, Cai Y, Sandhage KH. Free-standing microscale structures of nanocrystalline zirconia with biologically replicable three-dimensional shapes. J Mater Res 2005;20(2):282-7.

[10] Sandhage KH, Allan SM, Dickerson MB, Gaddis CS, Shian S, Weatherspoon MR, et al. Merging biological self-assembly with synthetic chemical tailoring: The potential for 3-D genetically engineered micro/nano-devices (3-D GEMS). Int J Appl Ceram Technol 2005;2(4):317-26.

[11] Losic D, Mitchell JG, Voelcker NH. Complex gold nanostructures derived by templating from diatom frustules. Chem Commun 2005;39:4905-7.

[12] Wee KM, Rogers TN, Altan BS, Hackney SA, Hamm C. Engineering and medical applications of diatoms. J Nanosci Nanotechnol 2005;5(1):88-91.

[13] Hamm CE, Merkel R, Springer O, Jurkojc P, Maier C, Prechtel K, et al. Architecture and material properties of diatom shells provide effective mechanical protection. Nature 2003;421(6925):841-3.
[14] Crawford SA, Higgins MJ, Mulvaney P, Wetherbee R. Nanostructure of the diatom frustule as revealed by atomic force and scanning electron microscopy. J Phycol 2001;37(4):543-54.

[15] Li XW, Li XX, Wang GC. Surface modification of diatomite using polyaniline Mater Chem Phys 2007;102(2-3):140-3.

[16] Tasdemirci A, Yuksel S, Karsu D, Gulturk E, Hall IW, Guden M. Diatom frustulefilled epoxy: experimental and numerical study of the quasi-static and high strain rate compression behavior. Mater Sci Eng a-Struct Mater Prop Microstruct Process 2008;480(1-2):373-82.

[17] Yuan P, He HP, Wu DQ, Wang DQ Chen LJ. Characterization of diatomaceous silica by Raman spectroscopy. Spectrochim Acta Part a-Mol Biomol Spectrosc 2004;60:2941-5.

[18] Liao L, Ren Y, Xiao T. In: Mai YW, Yu ZZ, editors. Polymer nanocomposites. Cambridge: Woodhead Publishing Limited; 2006. p. 330-56.

[19] Tsai WT, Lai CW, Hsien KJ. Characterization and adsorption properties of diatomaceous earth modified by hydrofluoric acid etching. J Colloid Interf Sci 2006;297(2):749-54. 